\title{
Incidence of proximal deep vein thrombosis in medical critical care patients
}

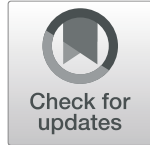

Chairat Permpikul', Walailak Chaiyasoot ${ }^{2}$ and Anupol Panitchote ${ }^{3^{*}}$

\begin{abstract}
Background: Approximately $13-31 \%$ of medical critical care patients develop deep vein thrombosis (DVT). However, there are very few reports regarding the incidence of DVT among Asian patients without routine prophylaxis. The objectives of this study were to assess the prevalence and incidence proportion of proximal DVT in Thai medical critical care patients not receiving thrombosis prophylaxis.

Methods: We conducted a prospective cohort study in medical critical care patients admitted to Siriraj Hospital, Thailand between November 2008 and November 2009. Patients were screened for proximal DVT by duplex ultrasonography performed 48 h, 7, 14 and 28 days after admission. Primary outcomes were prevalence and incidence proportion of DVT. Factors associated with the development of proximal DVT were evaluated by multivariate analysis.
\end{abstract}

Results: Of the 158 patients enrolled in the study, 25 had proximal DVT (15.8\%). Nine patients (5.7\%) had DVT on the first test at $48 \mathrm{~h}$, while 10 (6.3\%), 2 (1.3\%) and 4 (2.5\%) patients had developed DVT on days 7, 14, and 28, respectively. Thus, the prevalence at the beginning of the study was $5.7 \%(95 \% \mathrm{Cl} 2.6-10.5)$ and the incidence proportion was $10.1 \%(95 \% \mathrm{Cl}$ 5.9-15.9). The multivariate analysis showed that age (odds ratio [OR] per 1-year increase was 1.04, 95\% confidence interval [Cl] 1.01-1.07), female gender ( $\mathrm{OR} 4.05,95 \% \mathrm{Cl} 1.51-12.03)$, femoral venous catheter (OR 11.18,95\% $3.19-44.83$ ), and the absence of platelet transfusion (OR $0.07,95 \% \mathrm{Cl} 0.003-0.43$ ) were associated with the development of proximal DVT. Patients with proximal DVT had a longer hospital length of stay (22 days [IQR 11-60] vs. 14 days [7-23], $p=0.03$ ) and spent more time on mechanical ventilation (10 days (3.3-57) vs. 6 days $(3-12), p=0.053)$ than patients without DVT. Patient mortality was not affected by the presence of DVT $(52 \%$ vs. $38.3 \%, p=0.29)$.

Conclusions: Routine thromboprophylaxis is not used in our institution and the prevalence and incidence proportion of proximal DVT in Asian medical critical care patients were both substantial. Patients with older age, female gender, an intravenous femoral catheter, and the absence of platelet transfusion all had a higher chance of developing proximal DVT.

Keywords: Deep vein thrombosis, Critically ill patients, Prevalence, Incidence proportion, Ultrasonography

\section{Background}

Venous thromboembolism (VTE) is a life threatening clinical syndrome consisting of deep venous thrombosis (DVT) and pulmonary embolism [1]. This condition is

\footnotetext{
* Correspondence: panupo@kku.ac.th

${ }^{3}$ Division of Critical Care Medicine, Department of Medicine, Faculty of Medicine, Khon Kaen University, Khon Kaen, Thailand

Full list of author information is available at the end of the article
}

not uncommon in critically ill patients as the risk factors include prolonged immobilization, massive trauma, vascular injury, indwelling venous catheter, malignancy, and sepsis [2]. In certain patients, VTE may be asymptomatic [3]. An acute deterioration of hemodynamic status and gas exchange kinetics in patients with preexisting critical illness can leads to much worse outcomes. Pharmacologic thromboprophylaxis reduces the incidence of VTE

(c) The Author(s). 2022 Open Access This article is licensed under a Creative Commons Attribution 4.0 International License, which permits use, sharing, adaptation, distribution and reproduction in any medium or format, as long as you give appropriate credit to the original author(s) and the source, provide a link to the Creative Commons licence, and indicate if changes were made. The images or other third party material in this article are included in the article's Creative Commons licence, unless indicated otherwise in a credit line to the material. If material is not included in the article's Creative Commons licence and your intended use is not permitted by statutory regulation or exceeds the permitted use, you will need to obtain permission directly from the copyright holder. To view a copy of this licence, visit http://creativecommons.org/licenses/by/4.0/ The Creative Commons Public Domain Dedication waiver (http://creativecommons.org/publicdomain/zero/1.0/) applies to the data made available in this article, unless otherwise stated in a credit line to the data. 
[4], while adjunctive treatment with intermittent pneumatic compression did not have additional benefits in proximal lower limb DVT prevention [5]. However, this prevention strategy has not been implemented in our unit due to the belief that the risk of VTE is low in Asian patients [6-9]. Therefore, we conducted a prospective study in our institution to better examine the prevalence of VTE in our medical critical care patients. Prevalence and incidence proportion of proximal DVT and the factors associated with DVT development were evaluated.

\section{Methods}

\section{Study setting and patient population}

A prospective observational study of critically ill patients admitted to the medical ICU and medical wards of Siriraj Hospital, Mahidol University, Bangkok, Thailand between November 12008 and November 30 2009. The inclusion criteria were: (1) age > 18 years, (2) acute respiratory failure requiring invasive mechanical ventilation, (3) acute kidney injury requiring renal replacement therapy, and (4) sepsis defined according to SIRS criteria (ACCP/SCCM consensus conference 1992) [10]. Postoperative patients, patients with major trauma, or spinal cord injuries, or burns, and patients receiving anticoagulant therapy were excluded. This study was approved by the Siriraj Institutional Review Board (Si 545/2008). All patients or their next of kin provided written informed consent.

\section{Data collection and definitions}

Proximal DVT was diagnosed by compression venous ultrasonography using real-time B-mode on Philips/HP image point $\mathrm{Hx}^{\circ}$ multimodality ultrasound system with a $7.5 \mathrm{MHz}$ and/or a $5.5 \mathrm{MHz}$ linear transducer. The examination was begun just below then inguinal ligament by placing a linear transducer in a transverse position across the common femoral vein (CFV). Downward pressure was applied to the linear transducer until the vein collapsed completely (as seen on a gray-scale image) and then the transducer was relaxed. Downward pressure and relaxation were applied in 1-cm increments along the thigh from the CFV to the popliteal vein [11]. The deep veins in the lower leg were not examined. The compression venous ultrasonography was applied to both sides. Proximal DVT was diagnosed as a lack of full compressibility; a vein was considered fully compressible if no residual lumen was seen [12]. Color flow and spectral wave Doppler analysis were used for confirmation of proximal DVT.

Compression venous ultrasonography was first performed within $48 \mathrm{~h}$ of patient enrollment, and was repeated on day 7 , day 14 , and day 28 , or earlier if clinically indicated [13]. Prevalence of DVT was the percentage of DVT that were diagnosed within the first $48 \mathrm{~h}$ of study inclusion. Incidence of DVT was characterized by the number of DVT diagnosed after the initial $48 \mathrm{~h}$ tests $[14,15]$.

Compression ultrasonography with color Doppler imaging was performed by an experienced physician (Panitchote A) and recorded in a digital video disc that was reviewed by a radiologist (Chaiyasoot W). The radiologist did not know the test results and patient's clinical history. Interobserver reliability, kappa index, between the operator and the radiologist was 1.0.

The clinical pretest probability for DVT using Well's criteria [16] was evaluated during the first $24 \mathrm{~h}$ and on day 7, day 14, and day 28 of the study. The score was categorized into low, moderate, or high probability groups. Demographic data included age, sex, body mass index, admission diagnosis, severity of illness based on the acute physiology, age, chronic health evaluation (APACHE) II score, presence of malignancy, and a previous history of VTE. Treatments and interventions during the patient's hospital stay, such as renal replacement therapy (RRT), mechanical ventilation, platelet transfusion, vasopressor and inotropic drugs, neuromuscular blocking agents, and central venous catheter were collected. Patient outcomes consisted of duration of RRT, duration of mechanical ventilation, mortality, and length of hospital stay. The study data were collected and managed using REDCap [17].

\section{Statistical analysis}

The sample size was based on estimating a population proportion with an overall two-sided alpha level of 0.05 under the assumption that the incidence of DVT in critically ill patients would be $13 \%$. Prevalence and incidence proportion of proximal DVT were described as count and percentage with $95 \%$ confidence interval (CI). The factors associated with proximal DVT were explored. Continuous factors are presented as mean (standard deviation) or median (interquartile range, IQR). Discrete factors are presented as count and percentage. Two-sample $t$ test or Wilcoxon rank sum were used to compare continuous features, as appropriate. Chi square test or Fisher's exact test were used to compare discrete variables, as appropriate. The associations of these factors a with development of proximal DVT were analyzed by a generalized linear regression with a binomial distribution and logit link function. To build a multivariable regression model, univariable regression was first performed. The features that were significant at $p<0.1$ on univariable analysis were identified as potential predictor variables and entered into a multivariable regression model. Variable selection technique was performed using backward and forward stepwise model selection based on the Akaike information criterion. We 
checked multicollinearity in a final model using a variance inflation factor. Four-fold cross validation was used in estimating the generalization error. Area under the receiver operating characteristic (ROC) was calculated from four-fold cross validation for determination the model performance. We used $\mathrm{R}$ software version 3.5.2 for analysis ( $\mathrm{R}$ Foundation for Statistical Computing, Vienna, Austria) [18]. The level of statistical significance was set at $p<0.05$ (two tailed).

\section{Results}

A total of 170 patients were enrolled in this study. Of this, 12 patients $(7.1 \%)$ had inconclusive compression venous ultrasonography results and were excluded. Five patients had inconclusive results at day 14, four patients at day 7 , two patients at day 2 , and one patient at day 28 . Thus, the remaining 158 patients were analyzed. Median patient age was 64.5 years (IQR 47-76). Seventy-six patients (48.1) were female. The main etiologies of ICU admission were acute respiratory failure $(81.6 \%$ of the patients), followed by sepsis (78.5\%), acute kidney injury $(27.8 \%)$, congestive heart failure (7\%), chronic obstructive pulmonary disease with exacerbation $(6.3 \%)$, stroke (5.7\%), and acute respiratory distress syndrome (5.7\%). Mean APACHE II score was $21 \pm 7.5$ points (Table 1 ).

Twenty-five patients (15.8\%) developed proximal DVT at some point during the study. Nine of these (36.0\%) had proximal DVT upon the first test within $48 \mathrm{~h}$, while $10 \mathrm{pa}-$ tients (40\%), 2 patients (8\%), 4 patients (16\%) were diagnosed at days 7, 14, and 28 respectively. Hence, the point prevalence of proximal DVT at the beginning of the study was $5.7 \%$ (95\% CI 2.6-10.5) and the incidence proportion over 28 days was $10.1 \%$ (95\%CI 5.9-15.9). Low clinical probability of DVT was found common (76.6\%) inthe first 48 hours (Table 2). The clinical pretest probability of DVT at the first $48 \mathrm{~h}$ was significantly associated with ultrasound diagnosis $(p=0.02)$ and was a significant predictor of development of proximal DVT $(p=0.02)$.

The common femoral vein was the most common site of proximal DVT (21 patients [84\%], 95\%CI 63.9-95.5), followed by popliteal vein ( 8 patients [32\%], 95\%CI 14.953.5) and superficial femoral vein (7 patients [28\%], 95\%CI 12.1-49.4). In addition, 2 patients (8\%) had bilateral DVT. Symptomatic proximal DVT occurred in 16 patients (64\%) and sudden cardiac arrest suspected pulmonary embolism occurred in 1 patient.

\section{Factors associated with development of proximal DVT}

Patient age and gender were both associated with diagnosis of proximal DVT. The median age of patients with a diagnosis of proximal DVT (72 years) was significantly higher than patients without proximal DVT (61 years, $p=0.04$ ), and a higher proportion of proximal DVT
Table 1 Clinical characteristics of all cohort patients

\begin{tabular}{|c|c|c|}
\hline \multirow{2}{*}{$\begin{array}{l}\text { Characteristic } \\
\text { Age, median (IQR), years }\end{array}$} & \multicolumn{2}{|c|}{$\begin{array}{l}\text { All cohort patients } \\
(n=158)\end{array}$} \\
\hline & 64.5 & $(47-76)$ \\
\hline Female sex, n (\%) & 76 & $(48.1)$ \\
\hline Body mass index, median (IQR), $\mathrm{kg} / \mathrm{m}^{2}$ & 21.6 & $(19.1-24.2)$ \\
\hline \multicolumn{3}{|l|}{ Acute conditions, n (\%) } \\
\hline Acute respiratory failure & 129 & $(81.6)$ \\
\hline Sepsis & 124 & $(78.5)$ \\
\hline Acute kidney injury & 44 & $(27.8)$ \\
\hline Congestive heart failure & 11 & (7) \\
\hline COPD with acute exacerbation & 10 & $(6.3)$ \\
\hline Cerebrovascular accident & 9 & $(5.7)$ \\
\hline Acute respiratory distress syndrome & 9 & $(5.7)$ \\
\hline APACHE II, mean (SD), points & 21 & $(7.5)$ \\
\hline History of cancer, n (\%) & 25 & $(15.8)$ \\
\hline History of previous VTE, n (\%) & 2 & $(1.3)$ \\
\hline Renal replacement therapy (RRT), n (\%) & 25 & $(15.8)$ \\
\hline Duration of RRT, median (IQR), days & 3 & $(1-19)$ \\
\hline Platelet transfusion, n (\%) & 28 & $(17.7)$ \\
\hline Use of vasopressor or inotropes, n (\%) & 107 & $(67.7)$ \\
\hline Mechanical ventilation, n (\%) & 133 & $(84.2)$ \\
\hline Use of neuromuscular blocking agent, n (\%) & 24 & $(15.3)$ \\
\hline Central venous line, $\mathrm{n}(\%)$ & 85 & $(53.8)$ \\
\hline Internal jugular vein & 73 & $(46.2)$ \\
\hline Femoral vein & 24 & $(15.2)$ \\
\hline Subclavian vein & 8 & $(5.1)$ \\
\hline Cubital vein & 9 & $(5.7)$ \\
\hline
\end{tabular}

APACHE = acute physiology, age, chronic health evaluation, ARDS = acute respiratory distress syndrome, $C O P D=$ chronic obstructive pulmonary disease, $\mathrm{DVT}=$ deep vein thrombosis, $\mathrm{IQR}=$ interquartile range, NMBA = neuromuscular blocking agent, RRT = renal replacement therapy, $\mathrm{VTE}=$ venous thromboembolism

patients were female ( $68 \%$ vs. $44.4 \%, p=0.051)$. More patients with proximal DVT underwent renal replacement therapy (32\%) and femoral venous catheterization for renal dialysis (36\%) than patients without proximal DVT (12.8\% and $1.3 \%$, respectively). There was no association of proximal DVT with severity of illness, history of malignancy, receiving neuromuscular blocking agents, vasopressors, or mechanical ventilation (Table 3).

Table 2 Clinical probability of DVT at screening time in all cohort patients

\begin{tabular}{lcllllr}
\hline Clinical probability & Low & \multicolumn{3}{l}{ Moderate } & \multicolumn{2}{l}{ High } \\
\hline First 48 h, n (\%) & 121 & $(76.6)$ & 29 & $(18.4)$ & 8 & $(5.1)$ \\
Day 7, n (\%) & 52 & $(50)$ & 40 & $(38.5)$ & 12 & $(11.5)$ \\
Day 14, n (\%) & 31 & $(52.5)$ & 25 & $(42.4)$ & 3 & $(5.1)$ \\
Day 28, n (\%) & 16 & $(57.1)$ & 11 & $(39.3)$ & 1 & $(3.6)$ \\
\hline
\end{tabular}


Table 3 Factors associated with proximal deep vein thrombosis

\begin{tabular}{|c|c|c|c|c|c|}
\hline \multirow[t]{2}{*}{ Characteristic } & \multirow{2}{*}{$\begin{array}{l}\text { No DVT } \\
\text { (133) }\end{array}$} & \multirow{2}{*}{$\begin{array}{l}\text { DVT } \\
(25)\end{array}$} & \multirow[t]{2}{*}{$p$} & \multicolumn{2}{|c|}{ Multivariable analysis $^{a}$} \\
\hline & & & & $\begin{array}{l}\text { Adjusted OR } \\
(95 \% \mathrm{Cl})\end{array}$ & $p$ \\
\hline Age, median (IQR), years & $\begin{array}{l}61 \\
(45-75)\end{array}$ & $\begin{array}{l}72 \\
(64-80)\end{array}$ & 0.04 & $1.04^{\mathrm{b}}(1.01-1.07)$ & 0.02 \\
\hline Female sex, n (\%) & $\begin{array}{l}59 \\
(44.4)\end{array}$ & $\begin{array}{l}17 \\
(68)\end{array}$ & 0.051 & $4.05(1.51-12.3)$ & 0.01 \\
\hline BMI, median (IQR), kg/m² & $\begin{array}{l}21.6 \\
(19-24.2)\end{array}$ & $\begin{array}{l}21.3 \\
(19.2-24.4)\end{array}$ & 0.83 & & \\
\hline \multicolumn{6}{|l|}{ Acute conditions, n (\%) } \\
\hline Acute respiratory failure & $107(80.5)$ & $22(88)$ & 0.57 & & \\
\hline Sepsis & $104(78.2)$ & $20(80)$ & 0.99 & & \\
\hline Acute kidney injury & $37(27.8)$ & $7(28)$ & 0.99 & & \\
\hline Congestive heart failure & $9(6.8)$ & $2(8)$ & 0.69 & & \\
\hline COPD with acute exacerbation & $8(6)$ & $2(8)$ & 0.66 & & \\
\hline Cerebrovascular accident & $9(6.8)$ & $0(0)$ & 0.36 & & \\
\hline ARDS & $8(6)$ & $1(4)$ & 0.99 & & \\
\hline APACHE II, mean (SD), points & $20.8(7.7)$ & $22.3(5.7)$ & 0.26 & & \\
\hline History of cancer, n (\%) & $22(16.5)$ & $3(12)$ & 0.77 & & \\
\hline History of previous VTE, n (\%) & $1(0.8)$ & $1(4)$ & 0.29 & & \\
\hline RRT, n (\%) & $17(12.8)$ & $8(32)$ & 0.03 & & \\
\hline Duration of RRT, median (IQR), days & $2(1-19)$ & $6.5(2.5-13.3)$ & 0.68 & & \\
\hline Platelet transfusion, n (\%) & $27(20.3)$ & $1(4)$ & 0.08 & $0.07(0.003-0.43)$ & 0.02 \\
\hline Use of vasopressor or inotropes, n (\%) & $89(66.9)$ & $18(72)$ & 0.79 & & \\
\hline Use of NMBA, n (\%) & $18(13.6)$ & $6(24)$ & 0.22 & & \\
\hline Central venous line, n (\%) & $68(51.1)$ & $17(68)$ & 0.18 & & \\
\hline Internal jugular vein & $59(44.4)$ & $14(56)$ & 0.94 & & \\
\hline Femoral vein & $15(11.3)$ & $9(36)$ & 0.004 & $11.18(3.19-44.83)$ & $<0.001$ \\
\hline Subclavian vein & $5(3.8)$ & $3(12)$ & 0.11 & & \\
\hline Cubital vein & $8(6)$ & $1(4)$ & 0.99 & & \\
\hline Mechanical ventilation, n (\%) & $111(83.5)$ & $22(88)$ & 0.77 & & \\
\hline \multicolumn{6}{|l|}{$\begin{array}{l}\text { Clinical probability at first } 48 \mathrm{~h} \text {, } \\
\mathrm{n}(\%)\end{array}$} \\
\hline Low & $106(79.7)$ & $15(60)$ & 0.02 & & \\
\hline Moderate & $23(17.3)$ & $6(24)$ & & & \\
\hline High & $4(3)$ & $4(16)$ & & & \\
\hline
\end{tabular}

$\overline{\mathrm{APACHE}}=$ acute physiology, age, chronic health evaluation, $\mathrm{ARDS}=$ acute respiratory distress syndrome, $\mathrm{BMI}=$ body mass index, $\mathrm{Cl}=$ confidence interval, $\mathrm{COPD}=$ chronic obstructive pulmonary disease, $\mathrm{DVT}=$ deep vein thrombosis, $\mathrm{IQR}=$ interquartile range, $\mathrm{NMBA}=$ neuromuscular blocking agent, $\mathrm{OR}=$ odds ratio $\mathrm{RRT}=$ renal replacement therapy, VTE = venous thromboembolism

${ }^{a}$ Area under the receiver operating characteristic curve $(95 \% \mathrm{Cl})$ of multivariable analysis $=0.72(95 \% \mathrm{Cl} 0.60-0.85)$

ber 1 point increase

After multivariable analysis, development of proximal DVT was independently associated with age (OR 1.04, 95\%CI 1.01-1.07, $p=0.02$ ), female sex (OR 4.05, 95\%CI 1.51-12.03, $p=0.01$ ), presence of femoral venous catheterization (OR 11.18, 95\%CI 3.19-44.83, $p<$ 0.001 ), and the absence of platelet transfusion (OR $0.07,95 \%$ CI $0.003-0.43, p=0.02$ ) (Table 3). The area under the ROC of the multivariable model was 0.72 (95\%CI 0.60-0.85).

\section{Proximal DVT and patient outcomes}

Patients with proximal DVT had a higher duration of mechanical ventilation (10 [IQR 3.3-57] vs. 6 [IQR 3-12], $p=0.053)$ and a longer length of hospital stay (22 [IQR 11-60] vs. 14 [IQR 7-23], $p=0.03$ ). However, there was 
no association with hospital mortality (13 [52\%] vs. 51 [38.3\%], $p=0.29$ ) (Table 4).

\section{Discussion}

In our medical ICU, where routine prevention of venous thromboembolism is not employed, the occurrence of proximal DVT was $15.8 \%$. The prevalence at the beginning of the study was $5.7 \%$ while the incidence proportion during the first 28 days was $10.1 \%$. The common femoral vein was the most common site, followed by the popliteal vein and the superficial femoral vein. Threefourths of all DVTs developed within 7 days of the patients' inclusion in the study. Age, female sex, presence of femoral venous catheterization and absence of platelet transfusion were significant factors associated with development of DVT. Patients who had proximal DVT also had longer hospital stays and tended to spend more time on mechanical ventilation. However, there was no association between DVT and patient mortality. Despite the fact that this study was conducted more than ten years before this report, we believe that the data are sound because our institution's ICU practices regarding prevention and care of DVT remain unchanged.

The occurrence of proximal DVT in our MICU patients, who did not undergo thromboprophylaxis, is paralleled in other reports. Data collected from a Chinese ICU in 2008 [19], which focused on medical patients, disclosed a combined distal and proximal lower extremity DVT incidence of $19 \%$ and a proximal DVT incidence of $7.5 \%$. However, this study excluded patients with a femoral venous catheter, which was one of the factors associated with the development of proximal DVT in our study. One systematic review revealed that the DVT incidence ranged from 13 to $31 \%$ [20-24]. It is noticeable that the prevalence of DVT in our patients was similar to rates reported in Chinese populations and less similar to rates reported in western (Caucasian) populations. DVT was also found in patients receiving thromboprophylaxis, as noted in a prospective study of medical - surgical critically ill patients. In this study, the prevalence of DVT on ICU admission (within 48-72 h) was $2.7 \%$ and incidence was $9.6 \%$ over the ICU stay [16]. Another study from China revealed similar findings with the incidence of VTE in sepsis patients receiving thromboprophylaxis $9.95 \%$ at 28 days [25]. Another prospective study [26] revealed an overall VTE incidence, which included lower and upper extremity thrombosis, of $37.2 \%$ and use of central venous catheter and mechanical ventilation were identified as significant risks. Our study population consisted of a large proportion of sepsis patients (78.2\%), but the DVT incidence was not similarly high. The reasons might include the fact that our study did not include upper extremity examination and the ethnic differences between the studies. Therefore, our results fill the knowledge gap regarding DVT incidence in the Asian population.

Patient age, gender, presence of femoral venous catheter, and absence of platelet transfusion were all significant factors associated with the occurrence of thrombosis in our study. Age has been identified in several studies as a significant VTE risk [27-30]. Advancing age poses thrombotic risks because of increases in coagulation factors, platelet reactivity, and impairment of fibrinolytic activity [31]. As for the sex difference, while our study showed that being female was associated with developing proximal DVT, other studies have reported different results [32]. During childbearing years, the incidence rates of VTE are higher in females but the rates after age 45 years are higher in males [33]. Having a central venous catheter in place is a well-known DVT risk [34-36]. The femoral site poses a greater risk than subclavian locations [37] while the DVT rate of internal jugular veins is similar [38]. Blood transfusions are associated with DVT, particularly red blood cell and/or fresh frozen plasma transfusion but platelet transfusion is not associated with DVT [39]. However, the study of Cook showed that platelet transfusion is associated with DVT [14]. Although our study showed the opposite result, all the patients with platelet transfusion had thrombocytopenia as an indication for platelet transfusion. It might imply that thrombocytopenia may be a preventive factor for the development of DVT. However, future studies need to be answered.

Our study showed that patients with DVT had prolonged hospital stays and showed a marginal increase in time spent on mechanical ventilation while there was no association between DVT and patient mortality. However, the statistical power of this study for detection of mortality differences is insufficient. Our study was in line with the studies of Cook and Malato [14, 40].

Table 4 Patient outcomes by proximal deep vein thrombosis

\begin{tabular}{|c|c|c|c|c|}
\hline Outcome & $\begin{array}{l}\text { All } \\
(n=158)\end{array}$ & $\begin{array}{l}\text { No DVT } \\
(n=133)\end{array}$ & $\begin{array}{l}\text { DVT } \\
(n=25)\end{array}$ & $p$ \\
\hline Duration of MV, median (IQR), days & $6(3-13)$ & $6(3-12)$ & $10(3.3-57)$ & 0.053 \\
\hline Hospital length of stay, median (IQR), days & $14(8-27)$ & $14(7-23)$ & $22(11-60)$ & 0.03 \\
\hline Mortality, n (\%) & $64(40.5)$ & $51(38.3)$ & $13(52)$ & 0.29 \\
\hline
\end{tabular}

$\mathrm{DVT}=$ deep vein thrombosis, $\mathrm{IQR}=$ interquartile range, $\mathrm{MV}=$ mechanical ventilation 
We acknowledge a number of limitations in the current study. We did not confirm diagnosis of DVT by venography because it is difficult to perform in critically ill patients. Duplex ultrasonography is operator dependent, so to minimize bias, all studied were recorded and reviewed by a blinded radiologist. We had some inconclusive ultrasonography results because of edema in the lower extremities. The considerable number of inconclusive results could lead to underestimating the incidence. Moreover, our study did not systemically focus on pulmonary embolism except that patient developed clinically suspected pulmonary embolism. Future studies about the incidence of both DVT and pulmonary embolism will be needed.

\section{Conclusions}

The incidence proportion of proximal lower limb DVT among Asian medical critical care patients without thromboprophylaxis was slightly lower than reported for Caucasian populations. Patients at higher risks for development of proximal DVT were those with increased age, female gender, receiving a femoral venous catheter, and the absence of platelet transfusion. Patients with DVT stayed longer in hospital but did not show increased mortality. Based on our results, we would suggest routinely pharmacologic VTE prophylaxis in critically ill patients particularly a patient who is an elderly female and has a femoral venous catheter because the probability for development of DVT is more than $50 \%$.

\section{Abbreviations \\ APACHE: acute physiology, age, chronic health evaluation; Cl: confidence interval; CFV: common femoral vein; CUS: compression venous ultrasonography; DVT: deep vein thrombosis; ICU: intensive care unit; IQR: interquartile range; OR: odds ratio; ROC: the receiver operating characteristic; RRT: renal replacement therapy; VTE: venous thromboembolism}

\section{Acknowledgements}

We would like to acknowledge Dr. Glenn Neville Borlace, for editing English via the Publication Clinic at Khon Kaen University, Thailand.

\section{Authors' contributions}

CP designed the study, interpreted the data, and critically revised the manuscript. WC designed the study, participated in data collection, and critically revised the manuscript. AP designed the study, participated in data collection and cleaning, performed the analysis, developed the predictive model, wrote the first draft of the manuscript, and critically revised the manuscript. AP is also the guarantor, had full access to all the data in the study, and had final responsibility for the decision to submit for publication. All authors read and approved of the final manuscript.

\section{Funding}

This study received funding from Siriraj Hospital, Mahidol University, Bangkok, Thailand. The funding sponsor was not involved in study design, data collection, analysis, and manuscript writing.

\section{Availability of data and materials}

The datasets used and/or analyzed during the current study are available from the corresponding author on reasonable request.

\section{Declarations}

Ethics approval and consent to participate

This study was approved by the Siriraj Institutional Review Board (Si 545/

2008). All patients or their next of kin provided written informed consent

\section{Consent for publication}

Not applicable.

\section{Competing interests}

All authors report no competing interests relevant to this article.

\section{Author details}

'Division of Critical Care Medicine, Department of Medicine, Faculty of Medicine, Siriraj Hospital, Mahidol University, Bangkok, Thailand. ${ }^{2}$ Interventional Radiology Unit, Department of Radiology, Faculty of Medicine, Siriraj Hospital, Mahidol University, Bangkok, Thailand. ${ }^{3}$ Division of Critical Care Medicine, Department of Medicine, Faculty of Medicine, Khon Kaen University, Khon Kaen, Thailand.

Received: 7 March 2021 Accepted: 23 January 2022

Published online: 05 February 2022

\section{References}

1. Tritschler T, Kraaijpoel N, Le Gal G, Wells PS. Venous Thromboembolism: Advances in Diagnosis and Treatment. JAMA. 2018;320(15):1583-94.

2. Minet C, Potton L, Bonadona A, Hamidfar-Roy R, Somohano CA, Lugosi M, Cartier JC, Ferretti G, Schwebel C, Timsit JF. Venous thromboembolism in the ICU: main characteristics, diagnosis and thromboprophylaxis. Crit Care. 2015:19(1):287.

3. Ritchie G, McGurk S, McCreath C, Graham C, Murchison JT. Prospective evaluation of unsuspected pulmonary embolism on contrast enhanced multidetector CT (MDCT) scanning. Thorax. 2007;62(6):536-40.

4. Alhazzani W, Lim W, Jaeschke RZ, Murad MH, Cade J, Cook DJ. Heparin thromboprophylaxis in medical-surgical critically ill patients: a systematic review and meta-analysis of randomized trials. Crit Care Med. 2013:41(9): 2088-98.

5. Arabi YM, Al-Hameed F, Burns KEA, Mehta S, Alsolamy SJ, Alshahrani MS, Mandourah Y, Almekhlafi GA, Almaani M, Al Bshabshe A, et al. Adjunctive Intermittent Pneumatic Compression for Venous Thromboprophylaxis. N Engl J Med. 2019;380(14):1305-15.

6. White RH. The epidemiology of venous thromboembolism. Circulation. 2003:107(23 Suppl 1):14-8.

7. Jang MJ, Bang SM, Oh D. Incidence of venous thromboembolism in Korea: from the Health Insurance Review and Assessment Service database. J Thromb Haemost. 2011;9(1):85-91.

8. Lee $\mathrm{CH}$, Lin $\amalg$, Cheng $\mathrm{CL}$, Kao Yang $Y H$, Chen JY, Tsai LM. Incidence and cumulative recurrence rates of venous thromboembolism in the Taiwanese population. J Thromb Haemost. 2010;8(7):1515-23.

9. Prichayudh S, Tumkosit M, Sriussadaporn S, Samorn P, Pak-art R, Sriussadaporn S, Kritayakirana K. Incidence and associated factors of deep vein thrombosis in Thai surgical ICU patients without chemoprophylaxis: one year study. J Med Assoc Thai. 2015;98(5):472-8.

10. American College of Chest Physicians/Society of Critical Care Medicine Consensus Conference: definitions for sepsis and organ failure and guidelines for the use of innovative therapies in sepsis. Crit Care Med. 1992; 20(6):864-874

11. Fraser JD, Anderson DR. Deep venous thrombosis: recent advances and optimal investigation with US. Radiology. 1999;211(1):9-24.

12. Blaivas M. Ultrasound in the detection of venous thromboembolism. Crit Care Med. 2007;35(5 Suppl):224-34.

13. Kearon C, Julian JA, Newman TE, Ginsberg JS. Noninvasive diagnosis of deep venous thrombosis. McMaster Diagnostic Imaging Practice Guidelines Initiative. Ann Intern Med. 1998;128(8):663-77.

14. Cook D, Crowther M, Meade M, Rabbat C, Griffith L, Schiff D, Geerts W, Guyatt G. Deep venous thrombosis in medical-surgical critically ill patients: prevalence, incidence, and risk factors. Crit Care Med. 2005;33(7):1565-71.

15. Cook DJ, Crowther MA, Meade MO, Douketis J. Prevalence, incidence, and risk factors for venous thromboembolism in medical-surgical intensive care unit patients. J Crit Care. 2005;20(4):309-13. 
16. Wells PS, Hirsh J, Anderson DR, Lensing AW, Foster G, Kearon C, Weitz J, D'Ovidio R, Cogo A, Prandoni P. Accuracy of clinical assessment of deepvein thrombosis. Lancet. 1995;345(8961):1326-30.

17. Harris PA, Taylor R, Thielke R, Payne J, Gonzalez N, Conde JG. Research electronic data capture (REDCap)--a metadata-driven methodology and workflow process for providing translational research informatics support. J Biomed Inform. 2009;42(2):377-81.

18. R Core Team. R: A language and environment for statistical computing. Vienna: R Foundation for Statistical Computing; 2020.

19. Joynt GM, Li TS, Griffith JF, Gomersall CD, Yap FH, Ho AM, Leung P. The incidence of deep venous thrombosis in Chinese medical Intensive Care Unit patients. Hong Kong Med J. 2009;15(1):24-30.

20. Fraisse F, Holzapfel L, Couland JM, Simonneau G, Bedock B, Feissel M, Herbecq P, Pordes R, Poussel JF, Roux L. Nadroparin in the prevention of deep vein thrombosis in acute decompensated COPD. The Association of Non-University Affiliated Intensive Care Specialist Physicians of France. Am J Respir Crit Care Med. 2000;161(4 Pt 1):1109-14

21. Moser KM, LeMoine JR, Nachtwey FJ, Spragg RG. Deep venous thrombosis and pulmonary embolism: Frequency in a respiratory intensive care unit. JAMA. 1981;246(13):1422-4.

22. Cade JF. High risk of the critically ill for venous thromboembolism. Crit Care Med. 1982;10(7):448-50.

23. Geerts W, Cook D, Selby R, Etchells E. Venous thromboembolism and its prevention in critical care. J Crit Care. 2002;17(2):95-104.

24. Kapoor M, Kupfer YY, Tessler S. Subcutaneous heparin prophylaxis significantly reduces the incidence of venous thromboembolic events in the critically ill. Crit Care Med. 1999;27(12):A69.

25. Zhang C, Zhang Z, Mi J, Wang X, Zou Y, Chen X, Nie Z, Luo X, Gan R. The cumulative venous thromboembolism incidence and risk factors in intensive care patients receiving the guideline-recommended thromboprophylaxis. Medicine. 2019;98(23):e15833.

26. Kaplan D, Casper TC, Elliott CG, Men S, Pendleton RC, Kraiss LW, Weyrich AS Grissom CK, Zimmerman GA, Rondina MT. VTE Incidence and Risk Factors in Patients With Severe Sepsis and Septic Shock. Chest. 2015;148(5):1224-30.

27. Wilasrusmee C, Kiranantawat K, Horsirimanont S, Lertsithichai P, Reodecha P, Soonthonkit Y, Boonbavonrutanakun A, Tangsakuntong P, Panichvisai S, Jirasirithum S, Kittur DS. Deep venous thrombosis in surgical intensive care unit: prevalence and risk factors. Asian J Surg. 2009;32(2):85-8.

28. Caprini JA, Arcelus JI, Hasty JH, Tamhane AC, Fabrega F. Clinical assessment of venous thromboembolic risk in surgical patients. Semin Thromb Hemost. 1991;17(Suppl 3):304-12.

29. Harris LM, Curl GR, Booth FV, Hassett JM Jr, Leney G, Ricotta JJ. Screening for asymptomatic deep vein thrombosis in surgical intensive care patients. J Vasc Surg. 1997;26(5):764-9.

30. Koupenova M, Kehrel BE, Corkrey HA, Freedman JE. Thrombosis and platelets: an update. Eur Heart J. 2017;38(11):785-91.

31. Martinelli I, Bucciarelli P, Mannucci PM. Thrombotic risk factors: basic pathophysiology. Crit Care Med. 2010;38(2 Suppl):3-9.

32. Andreou ER, Koru-Sengul T, Linkins L, Bates SM, Ginsberg JS, Kearon C. Differences in clinical presentation of deep vein thrombosis in men and women. J Thromb Haemost. 2008;6(10):1713-9.

33. Heit JA, Spencer FA, White RH. The epidemiology of venous thromboembolism. J Thromb Thrombolysis. 2016;41(1):3-14.

34. Trottier SJ, Veremakis C, O'Brien J, Auer Al. Femoral deep vein thrombosis associated with central venous catheterization: results from a prospective, randomized trial. Crit Care Med. 1995;23(1):52-9.

35. Durbec O, Viviand X, Potie F, Vialet R, Albanese J, Martin C. A prospective evaluation of the use of femoral venous catheters in critically ill adults. Crit Care Med. 1997;25(12):1986-9.

36. Joynt GM, Kew J, Gomersall CD, Leung VY, Liu EK. Deep venous thrombosis caused by femoral venous catheters in critically ill adult patients. Chest. 2000;117(1):178-83.

37. Merrer J, De Jonghe B, Golliot F, Lefrant JY, Raffy B, Barre E, Rigaud JP, Casciani D, Misset B, Bosquet C, et al. Complications of femoral and subclavian venous catheterization in critically ill patients: a randomized controlled trial. JAMA. 2001;286(6):700-7.

38. Parienti JJ, Mongardon N, Megarbane B, Mira JP, Kalfon P, Gros A, Marque S, Thuong M, Pottier V, Ramakers M, et al. Intravascular Complications of Central Venous Catheterization by Insertion Site. N Engl J Med. 2015;373(13): 1220-9.
39. Ghazi L, Schwann TA, Engoren MC, Habib RH. Role of blood transfusion product type and amount in deep vein thrombosis after cardiac surgery. Thromb Res. 2015;136(6):1204-10.

40. Malato A, Dentali F, Siragusa S, Fabbiano F, Kagoma Y, Boddi M, Gensini GF, Peris A, Crowther M, Napolitano M. The impact of deep vein thrombosis in critically ill patients: a meta-analysis of major clinical outcomes. Blood Transfus. 2015;13(4):559-68.

\section{Publisher's Note}

Springer Nature remains neutral with regard to jurisdictional claims in published maps and institutional affiliations.
Ready to submit your research? Choose BMC and benefit from:

- fast, convenient online submission

- thorough peer review by experienced researchers in your field

- rapid publication on acceptance

- support for research data, including large and complex data types

- gold Open Access which fosters wider collaboration and increased citations

- maximum visibility for your research: over $100 \mathrm{M}$ website views per year

At BMC, research is always in progress.

Learn more biomedcentral.com/submissions 